\title{
$¿$ Existe el Consentimiento presunto?: la voluntad presunta como causa de justificación ${ }^{(* *)^{(*+*)}}$
}

\section{¿Does alleged consent exist?: the alleged will as underlying justification}

\author{
ES INCORRECTO RECURRIR ALTÉRMINO CONSENTIMIENTO PRESUNTO PARA HACER ALUSIÓN \\ A LOS CASOS EN LOS QUE EL TITULAR DEL BIEN JURÍDICO-PENAL SE VE IMPOSIBILITADO \\ DE MANIFESTAR SU VOLUNTAD, PRESUMIÉNDOSE SU CONSENTIMIENTO EN LA HIPÓTESIS \\ O FICCIÓN DE QUE EL MISMO HABRÍA CONSENTIDO, EN CASO DE CONOCER EL HECHO Y DE \\ TENER LA OCASIÓN PARA HACERLO.
}

\begin{abstract}
Resumen: En el presente artículo, la autora analiza la figura jurídica del consentimiento presunto, señalando su postura contraria a dicha formulación y proponiendo, en su lugar, el término voluntad presunta, por considerarlo más exacto para describir la ficción jurídica utilizada para recrear el momento en el que el titular del bien jurídico habría consentido la actuación del autor, en caso de haber conocido el hecho y de haberse encontrado en la posibilidad de brindar su consentimiento. En dicha línea, la autora repasa las teorías doctrinarias formuladas para explicar la naturaleza jurídica de la voluntad presunta, descartando que se trate de una causa de atipicidad penal y optando por considerarla una causa de justificación autónoma. Asimismo, la autora describe los requisitos que deberá tener esta voluntad presunta para ser considerada válidamente como una causa de justificación autónoma, diferenciándola de otros supuestos como la subrogación. Finalmente, la autora hace una revisión de las dos categorías donde puede presentarse la voluntad presunta: las actuaciones en interés ajeno y las actuaciones en interés propio.
\end{abstract}

Palabras Clave: Consentimiento Presunto - Voluntad Presunta - Causa de Justificación - Causa de Atipicidad - Subrogación - Requisitos - Actuaciones en Interés Ajeno - Actuaciones en Interés Propio

${ }^{*}$ Abogada por la Pontificia Universidad Católica del Perú. Magister en Derecho Penal por la Universidad de Salamanca. Profesora Ordinaria Asociada de la Facultad de Derecho de la Pontificia Universidad Católica del Perú en la que dicta Derecho Penal. Socia fundadora del Estudio Padilla \& Chang Abogados. Correo electrónico: romy.chang@pucp.edu.pe

${ }^{* *}$ La autora agradece a la Beca Iberoamericana Jóvenes Profesores e Investigadores otorgada por el Banco Santander por permitir la realización del presente trabajo académico.

$\left.{ }^{* * *}\right)$ Nota del Editor: este artículo fue recibido el 27 de mayo del 2017 y su publicación fue aprobada el 21 de junio del mismo año. 


\author{
¿Existe el consentimiento presunto?: la voluntad presunta como causa de \\ justificación
} ¿Does alleged consent exist?: the alleged will as underlying justification

\begin{abstract}
In this paper, the author analyzes the alleged consent, stating their stance against it and proposing, instead, the alleged will, considering that the last is right for describe the legal fiction used to recreate the moment in which the legal holder knows the fact and have the possibility of providing consent to excute the 'ilicit' action. In this line, the author reviewed the theories that explain the legal nature of the alleged will, rejecting it as a noncriminal behavior and considering it an autonomous underlying justification. Also, the author describes the requirements of this alleged will, differentiating it from other situations as subrogation. Finally, the author makes a review of the two categories where the alleged will occurs: performances in foreign interest and actions on self-interest.
\end{abstract}

Keywords: Alleged Consent - Alleged Will - Underlying Justification - Non-criminal Behavior - Subrogation - Requirements - Performances in Foreing Interest - Actios on Self-interest

\section{Introducción}

El consentimiento presunto se genera en los supuestos en los que el titular del bien jurídico se ve imposibilitado de consentir (manifestar su voluntad), presumiéndose su consentimiento en la hipótesis o ficción de que él habría consentido, en caso de conocer el hecho y tener la ocasión para hacerlo. Ejemplos de ello ocurren: cuando una persona causa lesiones a quien está a punto de ahogarse para poder salvarle de una muerte inminente, cuando el médico decide ampliar el campo operatorio de una intervención ya iniciada sin que el paciente se dé cuenta por estar bajo los efectos de la anestesia, cuando alguien ingresa al huerto de otro para coger un fruto que por maduro ha caído del árbol, cuando alguien coge una revista y deja el dinero en el mostrador del quiosco de periódicos ante la ausencia del vendedor, cuando alguien usa el móvil olvidado de su mejor amigo para realizar una breve llamada, entre otros.
El problema es que en estos casos, en la práctica, realmente no existe un consentimiento, sino una suposición de que el titular del bien jurídico, de conocer las circunstancias específicas, lo hubiese prestado; razón por la que no puede afirmarse que en estos supuestos el individuo haya hecho uso de su autonomía de la voluntad para tomar una decisión; siendo imposible alegar la concurrencia de una causa de atipicidad por consentimiento en la lesión del bien jurídico (el consentimiento nunca existió y no puede importar la no vulneración del bien protegido) (Chang 2015, 205 y siguientes) ${ }^{(1)}$. En esta línea, Roxin señala:

\begin{abstract}
"En efecto, mientras que el consentimiento es una expresión de la libertad de actuación del titular del bien jurídico y por tanto el que obra con consentimiento no lesiona los bienes jurídicos de aquél, quien invoca un consentimiento presunto se interfiere sin permiso, y por ello realizando el tipo delictivo, en los bienes jurídicos de otro, (...) el consentimiento presunto es una construcción normativa, mientras que el consentimiento efectivo es una manifestación de voluntad" (Roxin 1997, 765).
\end{abstract}

\section{Incorrecta referencia al consentimiento presunto}

En la medida en que en el consentimiento presunto, en realidad, no existe consentimiento o disposición alguna (sino sólo una construcción normativa ficticia) ${ }^{(2)}$, considero

(1) En anterior trabajo he dejado establecido que el consentimiento en el ámbito jurídico penal constituye en todos los casos una causa de exclusión del tipo (atipicidad), por no generar la lesión o puesta en peligro del bien jurídico protegido. Así, la sola configuración de la conducta típica no es suficiente para afirmar la existencia de un delito, haciéndose necesaria la vulneración de un bien jurídico penal y, a su vez, la lesión o afectación de la posibilidad de autorrealización de la persona; de manera que, el consentimiento válido del titular del bien jurídico, al convertir lo ilícito en lícito, evita que las normas penales se tornen en obstáculos para la autorrealización personal y permite que cada persona alcance la misma conforme con su ética personal y en el marco del entorno social que el Estado busca proteger.

(2) En contra, Mezger, para quien el consentimiento presunto no es una construcción ficticia, sino "(...) una interpretación de la dirección de la voluntad del supuestamente lesionado teniendo en cuenta todas las circunstancias del caso" (Mezger 1955), 433. Discrepo de lo expuesto por este autor, en tanto el hecho de que el fundamento del denominado consentimiento 
Romy Alexandra Chang Kcomt

que el nombre utilizado para esta figura no resulta correcto y puede dar lugar a confusión; siendo que incluso hay quienes en la doctrina prefieren hacer referencia a "la presunción (judicial) del consentimiento" (Mezger 1955, 432) y no al consentimiento presunto.

En mi opinión, en estos casos, en tanto no existe un real consentimiento anterior a la lesión o puesta en peligro del bien jurídico, el uso de este término no resulta acertado, siendo preferible utilizar el término voluntad presunta, nombre que propongo a fin de evitar confusiones terminológicas; sobre todo cuando la voluntad presunta, a diferencia del consentimiento, no operaría como una causa de atipicidad, sino como una causa de justificación autónoma(3). En lo que sigue, entonces, conforme con lo aquí propuesto, se usará el término voluntad presunta, en lugar del denominado en la doctrina como consentimiento presunto.

\section{Naturaleza Jurídica}

La voluntad presunta, en la medida que no supone una disposición que elimine una lesión o puesta en peligro del bien jurídico y, por tanto, convierta a la conducta en atípica (como sí ocurre con el consentimiento real), no puede considerarse una causa de atipicidad; constituyendo una causa de justificación extralegal.

En igual línea se ha pronunciado un buen sector de la doctrina. Así, a título de ejemplo, se tiene a Jescheck y Weigend, quienes la consideran "(...) una causa de justificación sui generis que, no obstante, conecta con la posibilidad de prestación del consentimiento por parte del bien jurídico" (Jescheck y Weigend 2002, 413-414). Para Roxin, constituye una causa de justificación de derecho consuetudinario que se sitúa entre el consentimiento y el estado de necesidad justificante, estableciendo su carácter de causa de justificación autónoma y distinguiéndola de las figuras antes mencionadas (Roxin 1997,765).

Para Cerezo, si bien debe ser concebida como una causa de justificación independiente, por un tema de seguridad jurídica y por la posible existencia de abusos a los que la presunción del consentimiento podría dar lugar, no la considera necesaria; reconduciendo todos los supuestos a las otras causas de justificación existentes (estado de necesidad, obrar en cumplimiento de un deber o en el ejercicio legítimo de un derecho) (Cerezo 1998, 347). Para Mezger, también debe ser reconocida como una causa de justificación, aunque no esté prevista expresamente como tal en la ley (Mezger 1955, 433-434).

En torno a la naturaleza jurídica de la voluntad presunta, otro sector de la doctrina la considera como una causa de atipicidad, argumentando que en el caso de los bienes que considera disponibles, existe cierta equivalencia entre el consentimiento real y la presunción de voluntad; en esta línea, De la Mata señala
"será entonces el conocimiento de esta voluntad basándose en criterios corroborables objetivamente el que permita en determinados casos hablar no ya de una conducta típica pero justificada, sino de una conducta atípica, precisamente porque no se realiza el hecho descrito en la prohibición penal" (De la Mata 1997, 402-403).

No considero adecuada esta posición, en tanto no es posible efectuar equiparación alguna entre la voluntad presunta y el consentimiento real, debido a que en la primera no existe consentimiento alguno. Considerar a la voluntad presunta una causa de atipicidad supondría establecer que el bien jurídico nunca llegó a lesionarse, lo que no correspondería a la verdad, por no existir disposición real de parte del

presunto se encuentra en la teoría de la dirección de la voluntad, no hace que el mismo deje de ser una figura ficticia que no se condice con la realidad (el titular del bien jurídico no brinda su disposición sobre éste, siendo que incluso, puede darse el caso que luego discrepe de lo presumido por quien efectuó la disposición).

(3) En similar línea, Frister hace uso del término voluntad hipotética, aunque mantiene el término consentimiento presunto (Frister 2011), 316-317. 


\section{¿Existe el consentimiento presunto?: la voluntad presunta como causa de justificación}

¿Does alleged consent exist?: the alleged will as underlying justification

titular del bien (el consentimiento hipotético no puede equipararse a un consentimiento real) $)^{(4)}$.

En diferente línea, considerando a la voluntad presunta como una causa de inculpabilidad en los casos en los que la presunción no se condice con la voluntad del titular del bien jurídico, se han pronunciado Cobo del Rosal y Vives Antón, para quienes: "(...) si a la presunción no correspondiera la realidad, entonces serían de aplicación las reglas del error: el consentimiento presunto no aparecería, por consiguiente, como causa de justificación, sino como una causa de inculpabilidad" (Cobo y Vives 1999, 500); al respecto, considero que distinguir la naturaleza jurídica de la voluntad presunta, en función a si la presunción es o no confirmada por el titular del bien jurídico, no resulta lo más adecuado; en tanto en uno u otro caso, la misma sigue ostentado la naturaleza de causa de justificación; pudiendo variar el tratamiento del error sobre la misma, en tanto se trate de un error en el presupuesto de una causa de justificación (error de tipo) o de un error respecto a la existencia de la misma (error de prohibición).

Por otro lado, respecto a la naturaleza jurídica de la voluntad presunta, otro sector doctrinal, encontrándose de acuerdo en que la misma debe constituir una causa de justificación, pero en desacuerdo respecto de que deba ser una causa de justificación autónoma, ha buscado abarcarla a través del estado de necesidad. Así, Zaffaroni establece: “(...) el problema debe resolverse como un supuesto de estado de necesidad justificante (...) lo fundamental es que se cause un mal para evitar otro mayor e inminente. Es altamente probable que tratándose de evitar un mal mayor, el titular del bien hubiese actuado de la misma manera. (...)" (Zaffaroni 1981, 526). Para Stratenwerth, incluso en el caso que la decisión del autor, luego de ponderar todas las circunstancias, no coincida con la verdadera voluntad del lesionado, el mismo estaría exento de responsabilidad penal, "(...) puesto que, justamente, lo que sustenta la justificación no es la voluntad del afectado como tal, sino la necesidad de tomar la decisión" (Stratenwerth 2005, 190). En similar línea, aunque distinguiendo según se trate de bienes jurídicos disponibles o no disponibles, Mir Puig señala:

\begin{abstract}
"Cuando la intervención resulte necesaria para salvar un bien no disponible por su titular, como la vida, no hará falta acudir a la figura del consentimiento presunto, sino que bastará que el hecho resulte amparado por estado de necesidad (auxilio necesario). En cambio, si el bien en peligro es disponible por su titular, sólo es lícito intervenir si concurre consentimiento presunto, pues podría suceder que el titular prefiriese asumir la lesión del bien en peligro antes que la intervención lesiva necesaria para evitar aquélla" (Mir Puig 2016, 533-534).
\end{abstract}

También Romeo, para los casos de tratamientos curativos, establece: "Las ventajas del estado de necesidad, una vez comprobada la imposibilidad de contar el agente con el consentimiento del interesado, es que sus requisitos aparecen claramente delimitados en el Código Penal (...), y por lo que se refiere al tratamiento curativo, si se da la imposibilidad de obtención del consentimiento, el facultativo podrá acudir al estado de necesidad siempre que exista un peligro grave e inmediato para la salud -o la vida- del paciente; y que el facultativo no intervenga más que en lo imprescindible o necesario hasta que pueda obtener el consentimiento correspondiente" (Romeo 1981, 366-367).

No considero acertado incorporar a la voluntad presunta dentro del estado de necesidad justificante, por tener ambas figuras fundamentos totalmente diferentes. Así, mientras que la voluntad presunta (denominada por la doctrina consentimiento presunto) tiene como fundamento la voluntad hipotética del titular del bien jurídico; el estado de necesidad justificante tiene como

(4) No me parece correcta la afirmación efectuada por Segura García, respecto de que Günther mantiene la naturaleza de causa de atipicidad del consentimiento presunto (Segura 2000), 155. En realidad este autor considera al consentimiento y al consentimiento presunto como causas de exclusión del injusto penal, por calificarlas como "causas de justificación con eficacia justificante decreciente" (Günther 1995), 53-55. 
Romy Alexandra Chang Kcomt

fundamento la realización de una ponderación de intereses que necesariamente supone la elección del mal menor, la que no siempre va a coincidir con la voluntad del titular del bien jurídico, es decir, con el bien elegido al amparo de la voluntad presunta.

En esta línea, respecto a la voluntad presunta, Jescheck y Weigend señalan: "(...) aquí lo importante es la voluntad aquiescente del titular del bien jurídico, tal y como se habría mostrado ante el análisis de la situación fáctica, incluso aunque el resultado de la ponderación de intereses estuviera en contra de tal voluntad" (Jescheck y Weigend 2002, 413-414)(5). De manera que, si bien en muchos supuestos puede ocurrir que la voluntad presunta coincida con lo que hubiera elegido el titular del bien jurídico, esto no ocurrirá en todos los casos, lo que legitima que la misma sea considerada como una causa de justificación autónoma a las demás causas de justificación tradicionalmente recogidas por los ordenamientos jurídicos ${ }^{(6)}$.

\section{Diferencias entre la voluntad presunta y la subrogación (representación)}

De lo dicho, la voluntad presunta operará como causa de justificación autónoma en los casos en los que el titular del bien jurídico no pueda manifestar su consentimiento, pero, luego de analizadas las especiales circunstancias del caso concreto, el autor (quien lesiona o pone en peligro el bien jurídico) presume que el mismo aceptaría su disposición. Al respecto, debe precisarse que estos casos no deben ser confundidos con los supuestos en los que opera una subrogación del consentimiento por encontrarse imposibilitado o incapacitado para consentir el titular del bien jurídico (consentimiento brindado por un representante). Así, en los casos en los que exista un representante que pueda brindar el consentimiento por el titular del bien jurídico, no podrá decirse que exista una voluntad presunta; sino, por el contrario, habrá operado una subrogación que permitirá a dicho representante brindar un consentimiento expreso que excluirá la tipicidad de la conducta por la no lesión del bien jurídico protegido, es decir, habrá operado un consentimiento como causa de atipicidad. Esto ocurre, por ejemplo, en el caso de la operación de apéndice que tenga que practicarse a un menor de 5 años de edad, en estos casos, sus padres (quienes ejercen la patria potestad) brindarán el consentimiento expreso para la lesión del bien jurídico salud de su menor hijo, no existiendo una voluntad presunta; sino, por el contrario, un consentimiento expreso que incluso llegará, en este caso en concreto, a ser escrito. En tal sentido, en el consentimiento brindado por el representante (causa de atipicidad) siempre deberá cumplirse con la exteriorización de la voluntad (sea ya de forma expresa, tácita, o escrita, oral); mientras que en la voluntad presunta (causa de justificación autónoma) no existirá un consentimiento y operará una presunción respecto de que el titular del bien jurídico o su representante hubieran hecho de encontrarse en esa situación (un juicio hipotético sobre la base de criterios objetivos); operando, por ello, la voluntad presunta en los casos en los que el titular no pueda brindar su consentimiento y no exista tampoco un representante que válidamente pueda hacerlo por él.

En esta misma línea, sobre la voluntad presunta (aunque denominándola consentimiento presunto), Jescheck y Weigend señalan:

(5) En igual línea, se encuentran: (Roxin 1997), 766; (Bacigalupo 1995), 121; (Casas 1987), 106; sobre este punto Mezger precisa: "Se trata, por tanto -y en esto debe insistirse especialmente-, de determinar no lo que el supuesto ofendido hubiera razonablemente debido hacer en tal situación fáctica, sino cómo se hubiera comportado realmente (según toda previsión) con arreglo a su total dirección de voluntad personal” (Mezger 1955), 432. En contra, Cuello y Borja señalan "El consentimiento presunto requiere siempre una ponderación" (Cuello y Borja 2014), 92.

(6) Al respecto, Roxin, reconociendo la naturaleza de causa de justificación autónoma en la voluntad presunta, afirma: "De todos modos, el consentimiento presunto está próximo al estado de necesidad justificante en la medida en que la hipotética voluntad del sujeto en cuyos bienes se produce la ingerencia coincidirá en muchos casos con el resultado de una ponderación objetiva de intereses" (Roxin 1997), 766. 


\section{¿Existe el consentimiento presunto?: la voluntad presunta como causa de justificación}

¿Does alleged consent exist?: the alleged will as underlying justification

\begin{abstract}
"Aquí nos encontramos ante un consentimiento que aunque de acuerdo con las circunstancias podría ser prestado eficazmente, sin embargo o no existe o no puede ser recabado a tiempo porque el titular del bien jurídico o, en su caso, su representante legal, no está localizable o está inconsciente y necesitado de un tratamiento médico urgente (...)" (Jescheck y Weigend 2002, 414).
\end{abstract}

En contra se ha pronunciado Queralt, para quien la voluntad presunta debe prevalecer incluso sobre la voluntad del representante: "(...) para evitar posibles perjuicios posteriores, ha de prevalecer el consentimiento presunto a favor de la intervención; los representantes o los familiares podrán ayudar a formarse un criterio al médico, pero salvo aportación fehaciente de denegación explícita de consentimiento efectuada con anterioridad por el interesado, el facultativo está autorizado para intervenir. El posterior y eventual disgusto del interesado resulta irrelevante" (Queralt 2015, 97).

No considero adecuada la propuesta planteada por este autor, en tanto desconoce que la autorrealización personal tiene como fundamento la autonomía de la voluntad; además, olvida que la voluntad presunta debe ser aplicada de forma excepcional y siempre prefiriéndose la voluntad expresa (consentimiento) del titular o el de su representante. Así, la voluntad presunta se aplicará únicamente cuando el titular o su representante no puedan brindar el consentimiento que convierte en atípica la lesión o puesta en peligro del bien jurídico. Sólo cuando no exista representación o cuando el titular no pueda consentir, tendrá sentido plantearse la posible existencia de esta causa de justificación autónoma.

\section{Requisitos}

A la voluntad presunta, en cuanto le sean aplicables, le son exigibles para su validez los requisitos establecidos para el consentimiento real( ${ }^{(7)}$. En esta línea, quien invoque esta causa de justificación debe tener la capacidad de juicio necesaria para efectuar un juicio hipotético respecto de lo que habría querido el titular del bien jurídico; debe actuar de forma libre y espontánea, sin vicio de la voluntad alguno; debe referirse al momento del hecho a través de un juicio hipotético ex ante (es irrelevante la esperanza de una posterior aprobación), debe cumplir con los requisitos adicionales exigidos en el tipo (ejemplo: ausencia de precio o recompensa para la donación de órganos), entre otros.

Adicionalmente, la voluntad presunta debe ser aplicada de forma subsidiaria y excepcional, no pudiendo recurrirse a ella cuando sea posible recabar el consentimiento expreso del titular del bien jurídico o el de su representante ${ }^{(8)}$; es decir, sólo debe recurrirse a esta figura cuando "(...) no se puede esperar a que él mismo tomara la decisión, ya que una demora de la intervención lo privaría de toda posibilidad de elección o conllevaría riesgos desproporcionados para él" (Stratenwerth: 2005, 189).

Asimismo, considero que se deberá rechazar la voluntad presunta como causa de justificación en los casos en los que pueda presumirse que el titular del bien jurídico o su representante hubieran consentido en contra, no pudiendo desconocerse la autodeterminación del sujeto $^{(9)}$. Con mayor razón se debe rechazar en los casos en los que de forma expresa el titular del bien jurídico o su representante se hayan manifestado en contra de la disposición, sin importar lo irrazonable que ello parezca (en estos casos, podría plantearse la concurrencia de un estado de necesidad, pero no de la voluntad presunta) (Stratenwerth: 2005, 190)(10).

(7) En esta línea, por todos, veáse (Roxin 1997), 766; (Jescheck y Weigend 2002), 417; (Mir Puig 2016), 533-534; (Segura 2000), 156.

(8) En esta línea, por todos, veáse (Roxin 1997), 769; (Cuello y Borja 2014), 92. En contra, Tiedemann plantea la posibilidad de admitir la voluntad presunta para los casos de menoscabos insignificantes o transitorios, lo que es rechazado por Roxin (Roxin 1997), 769.

(9) En igual línea, Casas Barquero, quien señala: 'Por lo que, para que la justificación por consentimiento presunto pueda darse, no ha de infringirse la autodeterminación del sujeto" (Casas 1987), 104. 
Romy Alexandra Chang Kcomt

Respecto a esta opinión, en contra, se ha manifestado Mezger, quien afirma que "(...) el llamado consentimiento presunto puede a veces darse en contra de la voluntad expresamente declarada del titular del interés (...). La oposición del aparentemente lesionado puede tener su causa en una interpretación errónea del estado de hecho, en cuya hipótesis es indudable que si hubiera reconocido de modo exacto la situación (situación del consentimiento presunto), hubiera otorgado el consentimiento. El interés mismo del presunto ofendido determina que en tales supuestos prevalezca sobre su errónea declaración de voluntad su verdadera dirección de voluntad" (Mezger 1955, 433); (Rodriguez y Serrano 1994, 508).

Considero que este planteamiento va en contra de la naturaleza jurídica de la voluntad presunta como causa de justificación, la que tiene como fundamento la supuesta voluntad del titular del bien jurídico (siendo este elemento el que la diferencia respecto de otras causas de justificación); por ello, definitivamente, cuando el titular del bien o su representante se hayan pronunciado manifiesta o tácitamente en contra de la disposición, no podrá justificarse esta conducta al amparo de la voluntad presunta, teniendo que analizarse en el caso concreto si concurren los requisitos de alguna otra causa de justificación.

\section{Supuestos de aplicación}

Aunque denominándolo consentimiento presunto, la doctrina distingue claramente dos grupos de casos en los que puede operar la voluntad presunta como una causa de justificación: las actuaciones en interés ajeno y las actuaciones en interés

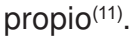

\subsection{Actuaciones en interés ajeno}

En un primer grupo se encuentran las actuaciones en interés ajeno, es decir, los casos en los que el autor (quien lesiona o pone en peligro el bien jurídico) interviene o deja de intervenir en la esfera jurídica de otro, en favor de este último, disponiendo sobre su bien jurídico y confiando al hacerlo en la aprobación posterior de éste. Se comprenden aquí los conflictos internos de intereses y bienes en el ámbito de la vida del titular de los mismos, los que deben ser solucionados a partir de una intervención externa, dada la imposibilidad del mismo titular o de su representante para brindar su consentimiento.

Al respecto, considero acertada la clasificación efectuada por Roxin (1997, 773-776) para establecer los diversos requisitos exigidos para la validez de la voluntad presunta, en función a las distintas situaciones y a las diversas decisiones que se presenten:

6.1.1 Decisiones vinculadas a la situación obje.tiva

En este grupo se comprenden las decisiones vinculadas a una situación real (objetiva), en las que la intervención del auxiliador no afecta o sólo afecta marginalmente el ámbito de la configuración más personal de la vida, como por ejemplo puede ocurrir cuando un vecino ingresa a la casa de otro para apagar un incendio que observa desde su ventana, o cuando alguien salva de morir ahogada a otra persona, aún a sabiendas que en el proceso de salvamento puede generarle lesiones; o cuando el guardián de un edificio cubre el auto de un vecino que se encuentra a la intemperie, para que no sea dañado con la pintura que pueda salpicar del pintado de la fachada del edificio contiguo.

Para estos casos, Roxin $(1997,773)$ propone como regla general la validez de la voluntad

(10) En similar línea, De la Mata señala: 'Y en ningún caso cabrá admitir el consentimiento presunto de constar la negativa expresa del titular a consentir la acción del autor del hecho o, incluso, datos razonables que permitan deducir dicha negativa a pesar de la ausencia de manifestación expresa del titular en ese sentido" (De la Mata 1997, 404). También Zaffaroni señala "No obstante, esta presunción se destruye cuando hay indicios de voluntad en contrario del titular del bien jurídico en peligro" (Zaffaroni 1981), 526.

(11) Sobre esta distinción, veáse (Jescheck y Weigend 2002), 415; (Roxin: 1997), 771-777; (Segura 2000), 152; (Casas 1987), 105-106. 


\section{¿Existe el consentimiento presunto?: la voluntad presunta como causa de justificación}

¿Does alleged consent exist?: the alleged will as underlying justification

presunta como causa de justificación, siempre y cuando se favorezca el interés claramente preponderante (luego de efectuada una ponderación objetiva) del titular del bien jurídico, a no ser que el sujeto activo (quien lesiona o pone en peligro el bien) tenga conocimiento de circunstancias que sean indicio de la opinión opuesta del titular del bien jurídico; caso en el que la voluntad presunta no tendría validez como causa de justificación. Pero, si no hubiese sido posible conocer nada más concreto sobre la postura del titular del bien jurídico, y el autor interviniera, por más que posteriormente resultase que el titular del bien o su representante no estuvieran de acuerdo con dicha intervención, igual la voluntad presunta tendría validez como causa de justificación.

\subsubsection{Decisiones vinculadas a la personalidad}

Conforme lo señala Roxin, se requerirá de este tipo de decisión "(...) cuando no se puedan encontrar criterios generalizables sobre lo correcto en una determinada situación, sino que ello dependa de la opinión sumamente individual del titular del bien jurídico" (Roxin 1997, 773); es decir, cuando sea muy difícil determinar cuál habría sido la voluntad del titular del bien jurídico o de su representante, cobrando especial relevancia su voluntad hipotética. Esto podría ocurrir, por ejemplo, si alguien leyera el mensaje por WhatsApp que llegara al móvil olvidado por un amigo, con la finalidad de poder avisarle respecto a una comunicación urgente que sabía estaba esperando para confirmarle una reunión de negocios; en este caso, difícilmente se podrá saber qué es lo que hubiera preferido el amigo: llegar a tiempo a la cita de trabajo o evitar que sus amistades se enteren de sus negocios personales.

Para estos casos, Roxin propone como regla general la regla inversa a las decisiones vinculadas a una situación objetiva: "el sujeto no puede partir del consentimiento presunto, a no ser que haya circunstancias especiales que hagan lógica la suposición de que el titular del bien jurídico está de acuerdo con la intromisión" (Roxin 1997, 774); exigiendo con ello, para la validez de la voluntad presunta como causa de justificación, que el sujeto (quien lesiona o pone en peligro el bien jurídico), antes de presumir su voluntad, conozca algo más exacto sobre la voluntad o postura del titular del bien o de su representante.
En el ejemplo propuesto, la voluntad presunta operaría como causa de justificación, si con anterioridad el dueño del teléfono hubiese pedido al autor que revisara sus WhatsApp, o le hubiera manifestado expresamente no tener problema con que otros se enteren de sus negocios personales; de existir estos indicios sobre la voluntad del mismo, por más que el titular posteriormente se mostrara en desacuerdo con que su amigo hubiese leído el mensaje de WhatsApp de su móvil, la voluntad presunta operaría como una causa de justificación. Si, por el contrario, no hubiese habido indicio alguno de la voluntad del titular y éste, con posterioridad, hubiera mostrado su disconformidad con el autor, éste debería responder por el tipo penal correspondiente.

También se puede incluir en estos casos las decisiones vinculadas con la corrección de niños ajenos. Así, si los padres se ausentaran y autorizaran expresamente a la nana a castigar moderadamente a sus hijos, si en una segunda oportunidad volvieran a ausentarse y olvidaran autorizar el castigo; válidamente la nana, en caso de imponer alguno, podría justificarse al amparo de la voluntad presunta ${ }^{(12)}$. En contra de aplicar esta causa de justificación se han manifestado Jescheck y Weigend, para quienes "Un derecho a la corrección de niños ajenos no puede ser apoyado sobre la idea del consentimiento presunto por parte de las personas facultadas para su educación; en el mejor de los casos puede plantearse la legítima defensa o una acción realizada en estado de necesidad" (Jescheck y Weigend 2002, 417), aunque admiten la posibilidad de plantear ciertas excepciones.

\subsubsection{Decisiones existenciales}

Este rubro comprende las decisiones sobre la vida y la muerte, respecto de las que la

(12) Al respecto, Roxin precisa que esto no sería válido para los castigos corporales, "Pues el hecho de que los padres se reserven a sí mismos ese método educativo aún no es razón suficiente para suponer que también van a estar de acuerdo con que otros castiguen a sus hijos" (Roxin 1997), 775. 
Romy Alexandra Chang Kcomt

voluntad presunta, por regla general, sí será considerada una causa de justificación válida. En este rubro incluyen también Cuello Contreras y Borja Mapelli las decisiones personales decisivas e irreversibles (ejemplo, intervención en accidente de víctima inconsciente) (Cuello y Borja 2014, 92).

Según Roxin, el fundamento para ello radica en el hecho de que "Cuando realmente está en juego la muerte, muchas personas revisan sus opiniones anteriores y quieren seguir viviendo; las decisiones existenciales de este tipo no se pueden anticipar ni siquiera por el propio afectado con reflexiones teóricas. Por ello, la mejor manera de servir a la autonomía del paciente es permitir que se le salve la vida, lo que le deja abierta al mismo la decisión posterior, incluso la de morir. En tal caso el consentimiento presunto justifica aunque posteriormente (sic) la persona salvada no esté de acuerdo con que se le haya salvado" (Roxin 1997, 776); con lo expuesto considera que, frente a una intervención médica en la que está en discusión la vida del paciente, siempre deberá preferirse salvarle la vida, aunque luego el titular no esté de acuerdo con ello, e incluso a pesar de que el mismo con anterioridad haya manifestado su consentimiento en contra (pues parte del supuesto que al último momento el titular puede cambiar de opinión).

Respecto a este punto, considero que fundamentar la voluntad presunta en el posible cambio de opinión del titular del bien, incluso en los casos en los que el mismo previamente había expresado su voluntad contraria, no es del todo acertado; ello, no porque la solución a la que se arriba no me parezca la correcta, sino porque la fundamentación de la misma responde más al fundamento del estado de necesidad justificante (ponderación entre dos males y elección del menor mal), que al fundamento que legitima la voluntad presunta como causa de justificación autónoma (voluntad del titular).

En virtud de lo expuesto, en estos casos, a fin de desnaturalizar el fundamento que legitima la voluntad presunta como causa de justificación, para definir si el autor actuó bajo el amparo del estado de necesidad justificante o de la voluntad presunta del titular del bien jurídico, deberá atenderse a las razones que motivaron su actuación. Así, por ejemplo, en caso de que un médico decidiera no efectuar a un paciente en estado de inconsciencia una trasfusión sanguínea, por llevar éste una medalla en el pecho en la que se declarara Testigo de Jehová y expresamente afirmara preferir morir antes que recibir una transfusión; en caso de que el paciente falleciera, no podría sancionarse al médico por homicidio, por haber actuado al amparo de la causa de justificación voluntad presunta. Mientras que, si en el mismo caso, el médico procediera a efectuar la transfusión y, con ello, a salvarle la vida, alegando una ponderación de intereses, tampoco podría ser sancionado, pudiendo alegar la causa de justificación estado de necesidad(13).

\subsection{Actuaciones en interés propio}

En este segundo grupo se encuentran los casos en los que el sujeto interviene o deja de intervenir en la esfera del titular del bien jurídico, en su propio interés; es decir, el sujeto dispone sobre los bienes jurídicos del titular, confiando al hacerlo en su aprobación posterior, sin que este último reciba beneficio o ventaja con dicha disposición. Se comprenden aquí los supuestos en los que sea presumible la renuncia por parte del afectado a sus propios intereses, en beneficio del autor (quien lesiona o pone en peligro el bien jurídico) o de un tercero. Así, por ejemplo se encuentra el caso del niño que recoge la fruta caída bajo los árboles ajenos en un año de exceso de producción, o de quien usa el teléfono celular de su mejor amigo para una breve llamada telefónica.

Para estos casos, Roxin propone aplicar como regla general la formulada para las

(13) Para Gómez Rivero, incluso en estos casos debe darse prioridad al respeto a la voluntad del paciente, en tanto "En el ámbito de los bienes disponibles, el estado de necesidad sólo puede encontrar acogida cuando con él se trata de salvaguardar un bien que su titular tiene interés en preservar, puesto que sólo cuando concurre esta premisa básica puede decirse que existe un interés digno de protección que pudiera entrar en colisión con el otro bien que finalmente se acaba lesionando" (Gómez 2008), 207. 


\section{¿Existe el consentimiento presunto?: la voluntad presunta como causa de justificación}

¿Does alleged consent exist?: the alleged will as underlying justification

decisiones vinculadas a la personalidad: "habrá de rechazarse el consentimiento presunto cuando no existan circunstancias concretas del caso particular que permitan inferir que el titular del bien jurídico está de acuerdo" (Roxin 1997, 776); siendo que, de encontrarse indicios que evidencien que el titular sí daría su aprobación, operaría la voluntad presunta como causa de justificación.

En contra se ha pronunciado Jakobs, para quien resulta demasiado arriesgado dar validez a la voluntad presunta en los casos en los que el titular del bien jurídico ni siquiera obtendrá beneficio alguno; por lo que, para este autor, "Siempre que en los supuestos de voluntad presunta en beneficio ajeno no concurra consentimiento -en su caso prestado de modo general o de modo concluyente-, aunque se trate de supuestos de injusto trivial, se realiza injusto" (Jakobs 1997, 544).

Considero adecuada la regla propuesta por Roxin en tanto, si bien la actuación realizada por el autor (quien lesiona o pone en peligro el bien jurídico) ni siquiera supone un beneficio para el titular del bien; sí resulta razonable validar la voluntad presunta en los casos en los que exista evidencia de que el titular del bien estaría de acuerdo (Cuello y Borja 2014, 92). Sin embargo, no estoy de acuerdo con aceptar lo propuesto por Roxin respecto de la validez de esta causa de justificación, para los casos en los que el menoscabo de intereses del titular del bien sea irrelevante: "La mera relación de personas muy conocidas y que se tienen simpatía sólo permitirá inferir el consentimiento presunto cuando el menoscabo de los intereses del titular del bien jurídico sea completamente irrelevante (como cuando se recoge la fruta que, si no, se va a corromper, o cuando se utiliza la bicicleta por un breve periodo de tiempo)" (Roxin 1997, 776-777). Considero que estos casos tampoco pueden quedar impunes a la luz de la voluntad presunta, dado que, por más insignificante que pueda resultar la lesión del bien menoscabado, en la medida en que no existe beneficio alguno para el titular del mismo y éste ni siquiera ha dado indicio alguno de su aceptación; nada justifica una intromisión en su esfera jurídica.

\section{A manera de conclusión}

Es incorrecto recurrir al término consentimiento presunto para hacer alusión a los casos en los que el titular del bien jurídico-penal se ve imposibilitado de manifestar su voluntad, presumiéndose su consentimiento en la hipótesis o ficción de que el mismo habría consentido, en caso de conocer el hecho y de tener la ocasión para hacerlo.

Ello debido a que en estos casos no existe manifestación de voluntad alguna (consentimiento), sino una construcción normativa ficticia que no se condice con lo que se entiende por consentimiento como causa de atipicidad penal. Por ello, en estos casos, propongo recurrir al término voluntad presunta, la que tiene como naturaleza la de ser una causa de justificación autónoma.

La voluntad presunta no deberá confundirse con los supuestos de subrogación del consentimiento o de representación, en los que un tercero consiente en lugar del titular del bien jurídico por encontrarse éste imposibilitado para consentir; dado que, en estos casos, sí nos encontraremos frente a una causa de atipicidad y no frente a una causa de justificación autónoma.

No obstante ello, la voluntad presunta deberá ser aplicada de forma excepcional y subsidiaria, respecto de los casos en los que sí sea posible obtener el consentimiento expreso del titular del bien jurídico o de su representante; diferenciándose claramente los contornos respecto de considerarla una causa de justificación en las actuaciones en interés ajeno y en las actuaciones en interés propio.

\section{Referencias bibliográficas}

Bacigalupo, Enrique. 1995. El consentimiento del lesionado en el Derecho y en la dogmática penal españoles. En Justificación y exculpación en derecho penal, ed. Albin Eser, Enrique Gimbernat y Walter Perrón. Madrid: Coloquio Hispano-Alemán de Derecho Penal.

Casas, Enrique. 1987. El consentimiento en el derecho penal. Córdoba: Universidad de Córdoba. 
Romy Alexandra Chang Kcomt

Cerezo, José. 1998. Curso de derecho penal español. Parte General. Vol. 2. Teoría Jurídica del Delito. $6^{a}$ ed. Madrid: Tecnos.

Chang, Romy. 2015. Naturaleza Jurídica del consentimiento de bienes jurídico-penales: Un análisis a la luz de la Constitución, Themis 67 (enero 2015): 205-16.

Cobo, Manuel y Tomás Vives. 1999. Derecho Penal. Parte General. $5^{\text {a }}$ ed. Valencia: Tirant Lo Blanch.

Cuello, Joaquín y Caffarena Borja. 2014. Curso de Derecho Penal. Parte General. $2^{a}$ ed. Madrid: Tecnos.

De la Mata, Norberto. 1997. "El consentimiento presunto ante comportamientos realizados en interés propio," Política criminal y nuevo derecho penal. Libro homenaje a Claus Roxin., ed. Jesús María Silva. Barcelona: Bosch.

Frister, Helmut. 2011. Derecho penal. Parte General, traducido de la cuarta edición por Marcelo A. Sancinetti, Buenos Aires: Hammurabi.

Gómez, María del Carmen. 2008. La responsabilidad penal del médico. $2^{\mathrm{a}}$ ed. Valencia: Tirant Lo Blanch.

Günther, Hans Ludwig. 1995. La clasificación de las causas de justificación en Derecho penal, traducido por Diego Manuel Luzón Peña de la versión en alemán publicada en 1992 En Causas de justificación y de atipicidad en Derecho penal, coords.Diego Manuel Luzón Peña y Santiago Mir Puig. Pamplona: Aranzadi.

Jakobs, Günther. 1997. Derecho Penal. Parte General. Fundamentos y teoría de la imputación, traducido por Joaquín Cuello Contreras y José Luis Serrano Gonzáles de Murillo. $2^{\mathrm{a}}$ ed. Madrid: Marcial Pons.

Jescheck, Hans-Heinrich y Thomas Weigend. 2002. Tratado de Derecho Penal. Parte General, traducido por Miguel Olmedo Cardenete. $5^{\mathrm{a}}$ ed. Granada: Comares.

Mezger, Edmundo. 1955. Tratado de Derecho Penal. Tom. I. Traducido por José Arturo Rodríguez Muñoz, Madrid: Editorial Revista de Derecho Privado.

Mir Puig, Santiago. 2016. Derecho Penal, Parte General. 10a ed. Barcelona: Reppertor.

Rodríguez, José María y Alfonso Serrano Gómez. 1994. Derecho penal español. Parte general. $10^{\mathrm{a}}$ ed. Madrid: Dykinson.

Romeo, Carlos María. 1981. El Médico y el Derecho Penal. I. La actividad curativa (licitud y responsabilidad penal). Barcelona: Bosch.

Roxin, Claus. 1997. Derecho Penal, Parte General. Fundamentos. La estructura de la teoría del delito. Tom. I, traducido de la segunda edición alemana por Diego-Manuel Luzón Peña, Miguel Díaz y García Conlledo y Javier Vicente Remesal. Madrid: Civitas.

Segura, María José. 2000. El consentimiento del titular del bien jurídico en derecho penal. Naturaleza y Eficacia. Valencia: Tirant Lo Blanch.

Stratenwerth, Günter. 2005. Derecho Penal. Parte General I. El Hecho Punible, traducido por Manuel Cancio Meliá y Marcelo A. Sancinetti, Navarra: Thomson-Civitas.

Queralt, Joan. 2015. Derecho Penal Español. Parte Especial. $7^{a}$ ed. Valencia: Tirant lo Blanch.

Zaffaroni, Eugenio Raúl. 1981. Tratado de Derecho Penal. Parte General. Tom. III. Buenos Aires: Ediar. 